\title{
La violencia sexual como práctica de guerra: implicaciones para la investigación y enjuiciamiento de crímenes atroces ${ }^{\star}$
}

\author{
Sexual Violence as a Practice of War: Implications \\ for the Investigation and Prosecution of Atrocity Crimes \\ Violência sexual como prática de guerra: implicações \\ para a investigação e acusação de crimes hediondos
}

\author{
Kim Thuy SeELINGER ${ }^{* *}$ \\ ELISABETH JEAN WOOD ${ }^{* \star \star}$
}

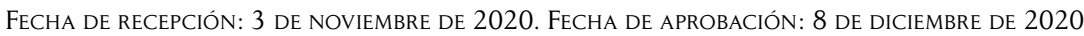

Doi: https://doi.org/10.12804/revistas.urosario.edu.co/sociojuridicos/a.10019

Para citar este artículo: Seelinger, K. T., \& Wood, E. J. (2021). La violencia sexual como práctica de guerra: implicaciones para la investigación y enjuiciamiento de crímenes atroces. Revista de Estudios Socio-Jurídicos, 23(1), 253-293. https://doi.org/10.12804/revistas.urosario.edu.co/sociojuridicos/a.10019

\section{RESUMEN}

En este documento, analizamos cómo el reciente interés de las ciencias sociales por la violencia sexual incurrida por actores armados incide en la investigación y enjuiciamiento de crímenes atroces. Nos enfocamos en un reto fundamental para intentar establecer qué tan frecuentemente la violación, como otras formas de violencia sexual, puede ser cometida por miembros de una organización armada sin que se la haya ordenado o autorizado como política. A esto lo denominamos práctica. Cuando ocurre con frecuencia, esta se rige por normas de género tanto de combatientes como de comandantes. La atención a estas dinámicas sociales refuerza el análisis de género de los fiscales y la investigación de un conflicto armado, esclareciendo las relaciones entre

* Agradecemos a Xabier Agirre Aranburu, Mayesha Alam, Magali Maystre, Guenael Mettraux, Mara Revkin, Patricia Viseur Sellers, Alex Whiting y a los editores por sus comentarios. También agradecemos a Julia Uyttewaal por su apoyo editorial y a Maria Gargiulo por su asistencia en la investigación. Esta es una traducción de Marco Danies de "Sexual Violence as a Practice of War: Implications for the Investigation and Prosecution of Atrocity Crimes", capítulo que será publicado en The Oxford Handbook of Atrocity Crimes, B. Hola, H. Nyseth Brehm, y M. Weerdesteijn (Eds.), Oxford University Press (OUP). Los derechos pertenecen a OuP.

** Profesora adjunta de investigación en la Brown School of Social Work, Public Health and Social Policy en la Universidad de Washington de St. Louis, donde también se desempeña como profesora visitante en la Facultad de Derecho y directora fundadora del Center for Human Rights, Gender and Migration. Correo electrónico: kseelinger@wustl.edu

${ }^{\star * \star}$ Profesora Crosby de Entorno Humano y profesora de Ciencias Políticas, Estudios Internacionales y de Área en la Universidad de Yale. Correo electrónico: elisabeth.wood@yale.edu 
diferentes actos de violencia. La acusación de violencia sexual que se presenta como práctica requiere caracterizaciones específicas del delito y del tipo de responsabilidad. Dado que se presenta como complicidad, tolerancia y previsibilidad, los modos de responsabilidad más relevantes son la ayuda y la incitación, responsabilidad de mando y asociación para delinquir.

Palabras clave: violación; violencia sexual; jerarquía de género; análisis de género; modos de responsabilidad; responsabilidad de mando.

\section{ABSTRACT}

We analyze the implications of recent social science on sexual violence by armed actors for the investigation and prosecution of atrocity crimes. We focus on a fundamental challenge that both rape and other forms of sexual violence may be committed frequently by members of an armed organization without being ordered or authorized as policy, which we term a practice. When frequent, it is driven by gender norms held by combatants and commanders alike. Attention to these social dynamics enhances prosecutors' gender analysis and investigation of an armed conflict, illuminating the relationships between different acts of violence. Charging sexual violence that occurs as a practice calls for specific characterizations of the offense and type of responsibility. Because it features complicity, tolerance, and foreseeability, modes of liability such as aiding and abetting, command/superior responsibility, and joint criminal enterprise are most relevant.

Keywords: Rape; sexual violence; gender hierarchy; gender analysis; modes of liability; command responsibility.

\section{RESUMO}

Analisamos como o recente interesse das ciências sociais pela violência sexual cometida por sujeitos armados influencia a investigação e o julgamento de crimes atrozes. Nos enfocamos em um desafio fundamental para tentar estabelecer o quanto que o estupro e outras formas de violência sexual podem ser frequentemente cometidos por membros de uma organização armada sem serem ordenados ou autorizados como política. Chamamos isso de prática. Quando ocorre com frequência, é regido por normas de gênero tanto de combatentes como de comandantes. A atenção a essas dinâmicas sociais reforça a análise de gênero dos promotores e a investigação de um conflito armado, esclarecendo as relações entre os diferentes atos de violência. A denúncia de violência sexual que se apresenta como prática requer caracterizações específicas do crime e do tipo de responsabilidade. Por se apresentar como cumplicidade, tolerância e previsibilidade, os modos de responsabilidade mais relevantes são: ajudar e incitar, responsabilidade de comando e associação para cometer um crime.

Palavras-chave: estupro; violência sexual; hierarquia de gênero; análise de gênero; modos de responsabilidade; responsabilidade de comando. 


\section{Introducción}

Tras siglos de aceptar la violación y otras formas de violencia sexual como daños colaterales inevitables en el curso de los conflictos armados, en las últimas décadas se ha estado prestando mayor atención al enjuiciamiento de estos delitos. Por ejemplo, entre 1943 y 1948, la Comisión de Crímenes de Guerra de la ONU guio a varios tribunales nacionales en sus juicios por violaciones cometidas durante la Segunda Guerra Mundial. Poco después, el Tribunal Militar Internacional para el Lejano Oriente consideró amplias pruebas de violencia sexual cometida por el ejército japonés en sus condenas generales de oficiales japoneses por crímenes de guerra. Algunas décadas más tarde, los tribunales penales internacionales para Ruanda (TPIR) y la ex-Yugoslavia (TPIY) abordaron decenas de casos, incluyendo violación y tortura sexual de niñas y mujeres Tutsi por parte de fuerzas ruandesas hutu en 1994, y de hombres, mujeres y niños musulmanes por parte de fuerzas de bosnios serbios a principios de la década de 1990. En 2002, el Estatuto de Roma de la Corte Penal Internacional (CPI) entró en vigor con la consideración más amplia que se haya dado hasta la fecha a los delitos de violencia sexual como delitos internacionales fundamentales. Más recientemente, las salas extraordinarias de los tribunales de Camboya y las salas africanas extraordinarias condenaron a altos funcionarios del Khmer Rouge y al expresidente de Chad, respectivamente, por crímenes internacionales de violencia sexual cometidos durante sus brutales regímenes.

No obstante, muchos actores armados en todo el mundo continúan violando a civiles, prisioneros de guerra e incluso a compañeros combatientes, a veces de forma masiva y casi siempre con impunidad. En su reciente informe anual al Consejo de Seguridad de la ONU (2019), el Secretario General informó que, en 2018, 53 organizaciones armadas participaron en violaciones y otras formas de violencia sexual contra civiles en 19 países afectados por conflictos.

El hecho de que la violación haya sido reconocida ahora como crimen de guerra, crimen de lesa humanidad y acto de genocidio, más que como un daño colateral inevitable de la guerra, es un logro notable del movimiento internacional de mujeres, impulsado en gran parte por la narrativa de que, cuando se presenta con frecuencia, la violación 
durante la guerra es una estrategia. La narrativa ha tenido un éxito extraordinario por varias razones. ${ }^{1}$ En ocasiones, es cierto, hace énfasis en que la violación no es un asunto privado, sino que es parte de la guerra. Sugiere que se debe procesar no solo a aquellos que cometen violaciones personalmente, sino también a sus comandantes. Si la violación es una estrategia, entonces se puede persuadir a los comandantes para que pongan fin a la violación, lo cual es una perspectiva atractiva.

Sin embargo, la naturaleza estratégica de la violación por parte de organizaciones armadas con frecuencia se presume, pero no se demuestra (Eriksson Baaz \& Stern, 2009; 2013; Wood, 2009; 2012; Agirre Aranburu, 2010; Boesten, 2010). El uso convencional sugiere que cuando la violación es una "estrategia", la organización armada (en algún nivel de mando) la ha adoptado intencionalmente para perseguir objetivos militares (Wood, 2018). No obstante, su adopción con fines militares se infiere a veces de sus efectos, como cuando una violación generalizada va seguida del éxodo de un pueblo de una región. En estos casos, los observadores presumen con poca evidencia que el éxodo fue el resultado esperado de una estrategia. Sin duda, la violación masiva se adopta a veces como estrategia precisamente con objetivos como la limpieza étnica o el desplazamiento forzado, pero para justificar el término "estrategia", académicos y analistas deberían no suponer, sino demostrar su adopción intencionada con objetivos militares.

Además, la violación y otras formas de violencia sexual ${ }^{2}$ pueden adoptarse como política organizativa, no con objetivos estratégicos, sino con otros objetivos como manejar la vida sexual y reproductiva de los combatientes (Wood, 2018). Estas otras formas, que incluyen la esclavitud sexual y la esterilización y desnudez forzadas, no han recibido tanta atención por parte de académicos y fiscales. Cuando alguna forma de violencia sexual es una política, ya sea estratégica o no, puede estar

1 Esta sección y las siguientes se basan en Wood (2018).

2 Tal como se usa aquí, la violencia sexual en tiempos de guerra (por combatientes) es más limitada que la violencia sexual relacionada con el conflicto tal como la usa la ONU, que incluye delitos sexuales cometidos por no combatientes en escenarios de colapso del Estado o en un clima de impunidad, y tráfico sexual en situaciones de conflicto (Oficina del Alto Comisionado de la ONU para los Derechos Humanos (2018). El concepto del patrón de violencia se deriva de Gutiérrez-Sanín y Wood (2020). 
autorizada por consignas como "estamos en guerra total", en lugar de haber sido ordenada por los comandantes.

Así mismo, miembros de una organización armada pueden haber cometido violaciones con frecuencia sin que estas hayan sido ordenadas o autorizadas como política organizativa. Si la violación es tolerada pero no ordenada o autorizada por los comandantes, entonces ocurre como una práctica, en lugar de una política, estrategia o táctica, de guerra (Wood, 2018). Cuando es frecuente y, por lo tanto, previsible, está impulsada por la dinámica social de género entre los combatientes, así como por la gratificación individual del combatiente.

En este texto analizamos las implicaciones para el enjuiciamiento de crímenes atroces internacionales a la luz de estos recientes hallazgos de las ciencias sociales. Somos conscientes de los inevitables desafíos de aplicar los conceptos de las ciencias sociales a los principios y la práctica del derecho penal internacional. Sin embargo, para investigadores y fiscales tiene un valor práctico en cuanto amplía nuestra comprensión de las muchas formas y razones por las que la violencia sexual ocurre en el contexto de los conflictos armados y la violencia masiva. Nos centramos en la violación u otras formas de violencia sexual como práctica, que plantean desafíos particulares para la parte acusadora. En tales entornos, los investigadores y fiscales no encontrarán registros de que la violación se ordenó o autorizó; más bien, deben buscar pruebas sobre si los comandantes la toleraron. La acusación de violencia sexual como práctica requiere caracterizaciones específicas del delito y del tipo de responsabilidad; como implica complicidad, tolerancia y previsibilidad, son particularmente importantes los modos de responsabilidad como la complicidad, la responsabilidad de mando/superior y la asociación para delinquir.

Primero, resumimos los hallazgos relevantes de las ciencias sociales, enfatizando que la violación puede ser frecuente sin que necesariamente sea una política organizacional; que cuando es una política puede ser autorizada, no ordenada, y que cuando la violación como práctica es frecuente, está impulsada por dinámicas sociales de género entre los combatientes, no solo por el oportunismo individual, y es tolerada por los comandantes en función de sus normas e intereses de género. Luego pasamos a las implicaciones legales. 


\section{Recientes hallazgos de las ciencias sociales sobre la violencia sexual durante los conflictos: política o práctica}

El hallazgo probablemente más importante de las ciencias sociales en relación con la violencia sexual en tiempos de guerra, también relevante para otros escenarios de violencia masiva, es que varía marcadamente en forma -violación, esclavitud sexual, tortura sexual, etc.-, objetivos y frecuencia entre las organizaciones armadas (Brownmiller, 1975; Wood, 2006; Cohen, 2013a; 2016; Cohen $\varepsilon$ Nordås, 2014). En cuanto a la focalización, por ejemplo, algunas organizaciones solo se enfocan en mujeres y niñas, mientras que otras también incluyen hombres.

Un hallazgo importante es que la violación por parte de combatientes no es inevitable en la guerra. Por ejemplo, en lo referente al Frente Farabundo Martí de Liberación Nacional, pocas veces se presentaron casos de violación durante la guerra civil de El Salvador (1980-1992), incluso cuando las fuerzas estatales participaron en violaciones generalizadas en el curso de masacres y la tortura sexual de muchos de los detenidos, niños y hombres, así como niñas y mujeres (Wood, 2009; Hoover Green, 2016; 2018). Por supuesto, hay una trascendental falta de denuncias de violaciones y otras formas de violencia sexual en la guerra. Sin embargo, se observa una clara variación después de que organizaciones de mujeres y de derechos humanos comenzaron a documentar intensamente su ocurrencia a mediados de la década de 1990 (Wood, 2014). Las diferencias documentadas son demasiado marcadas como para que solo reflejen diferencias en los informes.

Por varias razones, esta variación es relevante para la investigación y el enjuiciamiento de la violencia sexual durante la guerra y otras atrocidades masivas. El hecho de que algunas organizaciones armadas prohíban efectivamente la violación fortalece los motivos para hacer responsables a las organizaciones que no lo hacen. La variación en la forma sugiere que los investigadores deben considerar todo el espectro de la violencia sexual, incluyendo los actos aislados de violación oportunista; la violación como práctica; la esclavitud sexual, adoptada como política organizativa para manipular la vida sexual y reproductiva de los combatientes, y la violación cometida como política organizacional en medio del genocidio. 
Una política de violación u otras formas de violencia sexual pueden no ser ordenadas explícitamente, pero sí pueden estar autorizada. Los comandantes pueden autorizar la violación y a menudo otras formas de violencia contra civiles, combinando la retórica motivadora -"en la guerra todo se vale", "estamos en guerra total", "guerra sin límites", etc.con otras señales permisivas. Tales casos pueden ser más comunes que aquellos en los que se ordena. Por ejemplo, durante la "guerra contra el terrorismo" en los Estados Unidos, los líderes parecen haber autorizado, pero no ordenado directamente, el abuso sexual de detenidos como una variación de los llamados "interrogatorios mejorados" (Richardot, 2014; Wood y Bleckner, 2017).

Tomando la violación como ejemplo, hagamos referencia a la violación adoptada de manera intencional mediante órdenes o autorización de una organización armada en algún nivel de mando con objetivos militares inmediatos: la violación como estrategia. Por lo tanto, la violación como estrategia adoptada con objetivos militares es una subcategoría de la violación como política organizativa. Una organización puede adoptar deliberadamente, en algún nivel de mando, alguna forma de violencia sexual por razones que no sean inmediatamente militares. Algunas organizaciones adoptan políticas de esclavitud sexual, prostitución forzada y matrimonio o aborto forzado como una forma de recompensar a sus combatientes masculinos o de regular su vida sexual y reproductiva, no como una estrategia militar inmediata (Wood, 2009; 2014; 2018). Ejemplos de esto incluyen la esclavitud sexual de mujeres y niñas yazidi por parte del Estado Islámico y la prostitución forzada de las llamadas "mujeres de solaz" mantenidas en burdeles por el ejército japonés durante la Segunda Guerra Mundial. Otro ejemplo de tal regulación lo constituye la anticoncepción y el aborto forzados dentro de las filas de las Fuerzas Armadas Revolucionarias de Colombia (FARC).

\section{La violación como práctica de guerra}

En contraste con la violación u otras formas de violencia sexual por parte de organizaciones armadas que ordenan o autorizan la violación como política organizacional, la violación por parte de los soldados estadounidenses en la guerra de Vietnam fue frecuente, porque fue tolerada 
por los comandantes estadounidenses e impulsada por la dinámica social de los compañeros: la violación era una práctica de guerra. A raíz de la masacre y la violación de civiles en My Lai, soldados estadounidenses afirmaron que se les había ordenado o autorizado a matar civiles, pero no hicieron la misma afirmación acerca de los muchos incidentes de violación que describieron (Brownmiller, 1975; Peers, 1979; Weaver, 2010; Richardot, 2014; Wood, 2018). No obstante, varios de ellos mencionaron la presión social de sus compañeros para participar. Muy pocos soldados fueron procesados por violación.

En otros contextos de guerra, los patrones de violación también están bien caracterizados como práctica. Dara Kay Cohen (2013a; 2016) argumenta que la violación en grupo genera cohesión entre los desconcertados reclutas de insurgentes y militares estatales que dependen del secuestro y la presión, respectivamente. Arguye que, en estos casos, la violación no es adoptada intencionalmente por los comandantes como política. Más bien, los miembros de unidades pequeñas participan e insisten en que también participen todos los reclutas, incluidas las mujeres. Los mal pagados soldados del ejército de la República Democrática del Congo entienden la violación, ampliamente tolerada por los comandantes, como una compensación informal; es decir, pago por cuenta propia (Eriksson Baaz \& Stern, 2009; 2013).

\section{Condiciones para que la violación como práctica sea frecuente}

¿En qué condiciones es probable que la violación como práctica sea frecuente? Para esto deben cumplirse dos condiciones: al menos algunos combatientes deben participar y al menos un comandante tolera su ocurrencia. El que se cumplan estas condiciones depende de las preferencias, creencias y normas relativas a la agresión, sexualidad y género tanto de combatientes, como de comandantes.

¿Por qué los combatientes participan de la violación como práctica?

La primera condición, es decir, que algunos combatientes participen, se puede cumplir de dos maneras. La primera es que si la organización recluta a personas de una sociedad en la que la violación u otro abuso 
sexual contra civiles en general o un grupo objetivo en particular -por ejemplo, trabajadoras sexuales, minorías sexuales o de género u otros grupos sociales marginados- ya está permitido o es frecuente, y el grupo armado no reprime dichos actos mediante disciplina o socialización, los reclutas ingresan a las organizaciones con creencias y normas que construyen la agresión sexual hacia estas niñas y mujeres $-\mathrm{y}$ algunos niños, hombres y minorías sexuales y de género-como demostraciones apropiadas de masculinidad. En este caso, es decir, cuando los reclutas comparten la jerarquía de género de su grupo social en tiempos de paz, el orden de género en el que algunas masculinidades y feminidades dominan a otras (Sjoberg, 2016), la violación por parte de los combatientes se encuentra enmarcada en un continuo de violencia sexual que inicia en la paz y va hasta la guerra (Wood, 2014). ${ }^{3}$ El patrón durante la guerra refleja el patrón de la paz, aunque se puede manifestar con mayor frecuencia.

Sin embargo, las normas y jerarquías de género del combatiente pueden reflejar la socialización dentro de la organización, un segundo camino para la participación del combatiente. Un hallazgo particularmente importante de estudios recientes proporciona evidencia acerca de la fuerza de dicha socialización: en el 38\% de las guerras civiles entre 1980 y 2009 con informes numerosos o masivos de violación, se observa una asimetría sostenida: un lado se involucra en violación, mientras el otro no (Cohen, 2013a; 2016). Las características comunes a esa sociedad, tal como el patriarcado, no pueden explicar tales diferencias.

En el caso de la violación como práctica, la socialización relevante es la que se presenta entre pares. En las organizaciones armadas, los procesos sociales horizontales -aquellos entre pares o compañeros combatientes - son a menudo notablemente fuertes (Winslow, 1999). En medio de la soledad y el miedo, los combatientes tienen fuertes incentivos para ajustarse a las expectativas y al comportamiento de sus compañeros, incluso si el hecho de participar viola sus propias normas o las reglas de la organización. En organizaciones que prohíben la violencia sexual,

3 En contraste, algunos otros académicos ponen en un continuo toda la violencia sexual en tiempos de guerra y en tiempos de paz (Cockburn, 2004; Meger, 2016; Boesten, 2017). 
esta socialización horizontal puede ser lo suficientemente poderosa como para anular la socialización formal y la disciplina.

La violación como práctica, cuando es frecuente, está impulsada por esa dinámica social horizontal y de género de la socialización entre pares. Esa socialización, que en sí misma puede ser violenta, transforma las normas, inclinaciones y creencias del recluta e inculca una nueva jerarquía de género, para apoyar una frecuencia de violación significativamente mayor que en la sociedad civil, que a menudo incluye formas de violación excepcionalmente brutales. La violación en grupo probablemente es particularmente frecuente, un patrón común en las guerras civiles (Cohen, 2013b, 2016). Las mujeres combatientes también pueden participar, influenciadas por estos procesos de pares (Cohen, 2013b). En tales casos, esas diferentes formas y objetivos, y a menudo frecuencias más altas, sugieren que la violencia sexual en tiempos de guerra debe entenderse como una ruptura con los patrones de los tiempos de paz.

Las condiciones bajo las cuales las dinámicas sociales de los combatientes apoyan la violación como una práctica frecuente incluyen la presencia de normas y creencias de género que apoyan el ejercicio de la violación como actividad social y una jerarquía de género que legitima la focalización de grupos sociales particulares. Es más probable que la violación ocurra como práctica en unidades que no estén supervisadas, movilizadas lejos de su base de operaciones o que hayan estado movilizadas durante un periodo prolongado (Wood, 2018).

¿Por qué los comandantes toleran la violación como práctica?

¿Por qué al menos un comandante podría tolerar violencia que no es una política organizacional, la segunda condición para que se presente la violación como práctica? En algunos casos, un comandante no puede prohibirla de manera efectiva porque es posible que no tenga control sobre sus subordinados o que tenga algún control, pero lo dedica a otros asuntos (Butler et al., 2007).

Sin embargo, en muchos casos el comandante podría prohibir la violación, pero no lo hace (Wood, 2018). Las razones para no hacerlo pueden ser instrumentales: es posible que piense que una prohibición 
efectiva podría ser demasiado costosa porque requeriría disciplinar a subordinados que de otro modo son efectivos; podría desviar los escasos recursos hacia un tema que él considera sin importancia, o podría socavar la cohesión vertical al menoscabar el respeto de los subordinados. El comandante también puede tolerar la violación porque poco le preocupa el sufrimiento de las víctimas o simplemente porque prohibirla es demasiado problema. Un comandante pícaro puede participar o promover la violación desafiando las normas y reglas formales de la organización.

Por tanto, la tolerancia refleja las propias normas de género, creencias y jerarquía de género del comandante, quizás, de acuerdo a lo que le fue transmitido por socialización en instituciones especializadas de formación de oficiales, a pesar del daño a la organización.

\section{Diferenciar la violencia sexual como política y como práctica}

El hacer una evaluación de si una organización armada que viola con frecuencia ha adoptado la violación como política o tolera su ocurrencia constituye un desafío. El hecho de que la organización castigue o no a los combatientes por cometer violación puede contribuir a ver la diferencia. Si un combatiente es castigado por no cometer una violación, entonces la violación es una política. (Debe tenerse en cuenta que esta es una condición suficiente pero no necesaria: en el caso de que la violación esté autorizada pero no ordenada, la organización no castigaría a los combatientes que no violan). Si la organización prohíbe formalmente la violación, pero no la castiga o la castiga solo ocasionalmente, y no hay evidencia de que los comandantes la estimulen de manera afirmativa, entonces es probable que se trate de una práctica. Si los combatientes son castigados sistemáticamente por cometer violación, entonces no es una política. Pero si aún así continúa sucediendo, es una práctica tan profundamente arraigada -después de un periodo de tolerancia- que ocurre a pesar del castigo.

La evidencia de que una organización haya ordenado o autorizado el matrimonio forzado, la esclavitud sexual, la prostitución forzada o la violación indica claramente que ha adoptado deliberadamente esa forma de violencia sexual como política y, probablemente, también 
como estrategia. La evidencia de autorización incluye regulación de la participación de los combatientes en estas formas de violencia, por ejemplo, recompensando formalmente el valor o la lealtad con el acceso a las víctimas, mediante inspección médica u otra regulación de víctimas esclavizadas o prostituidas por la fuerza, y mediante la emisión de reglas que definan los contextos en los que la violencia es aceptable. (En organizaciones con instituciones débiles, lo que los combatientes entienden como "política" puede ser establecido por comandantes de bajo nivel, no por los líderes). La evidencia de que los combatientes se involucren en violaciones a lo largo de líneas estrechas, por ejemplo, contra detenidos políticos, pero no contra criminales, o solo contra civiles "enemigos", ofrece cierto apoyo a la interpretación de que se trata de una política; no obstante, esta evidencia no es suficiente, ya que los comandantes pueden tolerar la violación de algunos civiles, pero no de todos.

La prueba de que la violación es una práctica surge de la ausencia de evidencia de que sea una política, combinada con aquella de que sea tolerada por lo menos por algunos comandantes. Si los combatientes se involucran en cometer violaciones que no obedecen a una lógica organizacional, por ejemplo, violar a personas de etnia leal o neutral y no son castigados, es más probable que se trate de una práctica que de una política. Un patrón de participación desigual en violaciones entre unidades que no obedece a una lógica estratégica sugiere que algunos comandantes la toleran, pero no todos.

Los casos de ambigüedad deliberada son particularmente desafiantes. Un comandante puede promover la violación, pero de maneras que oculten ese hecho, protegiéndose así de dejar cualquier registro de haberla ordenado o autorizado. En tal "atrocidad por connivencia, (...el] resultado pretendido (...) es que el subordinado pueda afirmar haber actuado de conformidad con lo que creía que eran órdenes, mientras que el superior puede afirmar que nunca las impartió" (Osiel, 1998, p. 1038). Puede hacerlo porque entiende que es algo inaceptable o criminal o porque cree que las órdenes pueden ejecutarse de manera más efectiva si los combatientes sienten que pueden optar por violar (Richardot, 2014). También puede impartir lo que Richardot (2014,) denomina una orden "parcial": enunciando un objetivo sin más instrucciones, una forma 
de autorización ambigua (pp. 86-87), que invita a los combatientes a innovar en los medios, como en el caso del tratamiento a los detenidos por las fuerzas estadounidenses desde el 11 de septiembre.

Por ende, es importante reconocer como una forma de adopción de políticas el hecho de autorizar en lugar de ordenar a los combatientes a violar. Los comandantes autorizan la violación y a menudo otras formas de violencia contra civiles, combinando una retórica motivadora -"en la guerra todo se vale", "guerra total", "guerra sin límites", etc.- con connotaciones permisivas. Puede ser difícil demostrar que los comandantes tengan la intención de autorizar la violación, pero la combinación sostenida de retórica motivadora sin intento alguno de disciplinar a los combatientes sugiere fuertemente una autorización y, por lo tanto, una política.

Algunos casos caen en una "zona gris" situada entre la práctica y la política, como cuando la tolerancia generalizada y sostenida sugiere la autorización implícita como política (Wood, 2018). Investigadores de la ONU descubrieron que a los grupos de milicias aliados del gobierno en Sudán del Sur se les "permitía violar a mujeres en lugar de pagarles un salario", produciendo el espectro de que la violación evolucionó de ser una práctica para convertirse en una política (Asamblea General de la ONU, 2016).

\section{Implicaciones para la investigación y el enjuiciamiento}

A primera vista, la idea de la violencia sexual como práctica no parece cambiar mucho en lo referente a la investigación y enjuiciamiento de crímenes internacionales. En esta sección, comenzamos recordando que, para ser catalogada como crimen internacional, la violencia sexual nunca necesitó ser un "arma de guerra" estratégica y ordenada o una política organizacional con fines distintos a los militares, su ocurrencia como práctica puede ser suficiente. ${ }^{4}$ Luego destacamos, sin embargo,

4 En algunos casos, la violencia sexual "oportunista" cometida por satisfacción personal también puede constituir un crimen internacional, a condición de que los elementos del acto subyacente constituyan un crimen y se cumplan los elementos contextuales adicionales de 
tres formas en que la idea de la violencia sexual como práctica es importante para la investigación y el enjuiciamiento. En primer lugar, la atención a la violencia sexual como práctica puede enriquecer el análisis de género de un conflicto, lo que a su vez puede mejorar la detección de delitos internacionales o la comprensión de su dinámica. En segundo lugar, la atención a la violencia sexual como práctica puede abrir una gama más amplia de material probatorio y estrategias de investigación. En tercer lugar, la idea de la violencia sexual como práctica puede tener implicaciones para el enjuiciamiento de la violencia sexual relacionada con conflictos y atrocidades en lo relacionado a imputación de cargos, selección de acusados y caracterización de la responsabilidad.

\section{¿La violencia sexual como práctica es un crimen atroz?}

Cuando hablamos de "crímenes atroces", generalmente nos referimos a "crímenes internacionales fundamentales": crímenes de guerra, crímenes contra la humanidad y actos de genocidio. ${ }^{5}$ En esencia, lo que distingue a un crimen "regular" de uno internacional en este sentido es la existencia no solo de un acto criminal subyacente o "base criminal", sino si este acto estuvo acompañado de ciertos elementos "contextuales" o "introductorios". Estos elementos difieren entre los principales crímenes internacionales.

Para que un acto criminal individual constituya un crimen de guerra, ${ }^{6}$ debe tratarse de una violación de las leyes de la guerra. En general, el acto debe haber tenido lugar en el contexto de un conflicto armado, aunque ha habido cierta ambigüedad en cuanto a lo que realmente

crimen de guerra, crimen de lesa humanidad o genocidio. Este texto, sin embargo, se centra en la relevancia del concepto de práctica.

5 Este texto no se ocupa del cuarto crimen internacional fundamental del Estatuto de Roma: el crimen de agresión, que no fue parte operativa de la jurisdicción de la CPI hasta julio de 2018.

6 Estatuto de Roma, artículo 7; Convenio de Ginebra para mejorar las condiciones de los heridos y enfermos de las fuerzas armadas en campaña (Primer Convenio de Ginebra); Convenio de Ginebra para mejorar las condiciones de los heridos, enfermos y náufragos de las fuerzas armadas en el mar (Segundo Convenio de Ginebra); Convenio de Ginebra relativo al trato debido a los prisioneros de guerra (Tercer Convenio de Ginebra); Convenio de Ginebra relativo a la protección debida a personas civiles en tiempo de guerra (Cuarto Convenio de Ginebra). 
requiere este "nexo". En el TPIY, la Sala de Apelaciones de Kunarac ofreció una aclaración útil desde el principio:

El conflicto armado no tiene por qué ser causal de la comisión del crimen, pero la existencia de un conflicto armado debe haber jugado, como mínimo, un papel sustancial en la capacidad del perpetrador para cometer el crimen, su decisión de cometerlo, la forma en que se cometió o la finalidad para la que se cometió (Sentencia, Caso Fiscal c. Dragoljub Kunarac y otros, párr. 58).

Para que un acto constituya un crimen de lesa humanidad, por lo general, debe ser parte de un ataque generalizado o sistemático contra una población civil y perpetrado por alguien que tenga conocimiento de ese ataque más amplio. ${ }^{7} \mathrm{El}$ acto subyacente, en este caso, alguna forma de violencia sexual, no tiene por qué ser en sí mismo generalizado o sistemático, simplemente debe formar parte de ese ataque más amplio contra civiles. El TPIY, en su fallo de apelación a la sentencia de Tadic, aclaró que, si esos requisitos fundamentales se cumplen, no importa si el acto se cometió por motivos personales (Sentencia, Caso Fiscal c. Dusko Tadic, párr. 248). Además, en su fallo a la apelación de la sentencia de Kunarac señaló que no es necesario que tal acto se cometa en medio del ataque contra civiles para que constituya un crimen de lesa humanidad, pudo haber sido cometido a cierta distancia (Sentencia, Fiscal c. Dragoljub Kunarac et al., párr. 100). ${ }^{8}$

Por último, ciertos delitos también pueden constituir un acto de genocidio si se cometen con la intención de destruir, total o parcialmente, un "grupo nacional, étnico, racial o religioso" (Convención sobre Prevención y Castigo del Delito de Genocidio, artículo 2). Aunque la violación y otras formas de violencia sexual no se enumeran específicamente en la Convención sobre Genocidio, en general, se las ha caracterizado como

7 Esta definición se refleja en el artículo 5 del Estatuto actualizado del TPIY (2009) y el artículo 2 del Estatuto del Tribunal Especial para Sierra Leona -SCSL, por sus siglas en inglés- (2002). Los estatutos de otros tribunales han incluido ligeras variaciones, por ejemplo, el artículo 7 del Estatuto de Roma de la CPI requiere, además, conocimiento del ataque más amplio.

8 Ver también: Decision on the confirmation of charges, Fiscal c. Germain Katanga y Mathieu Ngudjolo Chui, párr. 380. 
"daño físico y mental grave (...o comol medida de imposición destinada a prevenir nacimientos". 9 Fue el caso del TPIR, el que confirmó que la violación y la mutilación sexual pueden constituir actos de genocidio siempre que se cometan con la intención necesaria (Sentencia, Fiscal c. Jean-Paul Akayesu, párrs. 507-508).

A pesar de las ligeras variaciones en las definiciones de los tribunales de estas tres categorías principales de delitos internacionales, la comisión "estratégica" de un acto delictivo subyacente o, más generalmente, su adopción como política organizativa no es técnicamente un requisito para ninguno de ellos. ${ }^{10}$ Como se señaló anteriormente, el establecimiento de un crimen de guerra requiere la demostración de una conexión entre el acto subyacente y el conflicto armado, pero este nexo no requiere prueba de una estrategia militar o política organizacional per se. En el caso de los crímenes de lesa humanidad, hay formas para que el acto delictivo subyacente forme parte de un ataque más amplio contra una población civil sin ser técnicamente "estratégico". En cuanto al genocidio, debe existir la intención de destruir la población objetivo debido a las características o creencias de los miembros del grupo, pero en términos legales, intención es lo mismo que una estrategia militar. ${ }^{11}$ Estas distinciones dan pie para que actos de violencia que no son una estrategia ni una política organizativa constituyan crímenes internacionales, a condición de que se demuestre que cumplen con los elementos contextuales descritos anteriormente. Esto incluye una miríada de actos de violencia sexual "no estratégica" cometidos por combatientes, que son tolerados, mas no ordenados ni autorizados por los comandantes.

Dando una mirada retrospectiva a la década de 1940, aunque los delitos sexuales no siempre han sido priorizados para el enjuiciamiento

9 Véase, por ejemplo, Sentencia Fiscal c. Radovan Karadzic (IT-95-5 / 18-AR98bis.1), Sala de Apelaciones, 11 de julio de 2013, párrs. 36 a 37; véase también Sentencia, Fiscal c. Athanase Seromba (ICTR-2001-66-A), Sala de Apelaciones, 12 de marzo de 2008, párr. 46.

10 El artículo 8 del Estatuto de Roma dispone: "La Corte tendrá jurisdicción con respecto a los crímenes de guerra, en particular cuando se cometan como parte de un plan o política o como parte de una comisión a gran escala de tales crímenes". Sin embargo, esta es una política de priorización y consideración jurisdiccional, no un elemento de definición de crímenes de guerra perse.

11 Aunque, en la práctica, los actos genocidas se cometen típicamente como parte de una campaña estratégica más amplia basada en intención genocida. 
como delitos internacionales, durante décadas los tribunales han considerado una amplia gama de delitos sexuales. Ciertamente, muchos enjuiciamientos por delitos sexuales se centraron en actos que claramente se cometieron para promover una política estratégica. Tomemos, por ejemplo, los miles de matrimonios forzados orquestados por los Jemeres Rojos en Camboya entre 1975 y 1979, que formaron parte de una política nacional para regular la familia y aumentar la población del país (Resumen de Sentencia, Caso No. 002/02 contra Nuon Chea y Khieu Samphan, párrs. 39-41). ${ }^{12}$

Sin embargo, los juicios también han involucrado actos de violencia sexual que no pueden ser caracterizados como particularmente estratégicos o dictados por la política organizacional. Los hechos del juicio de 1945 del general Yamashita Tomoyuki ante una comisión militar de los Estados Unidos en Filipinas son relevantes, a pesar del contexto de "justicia de los vencedores" en el que se llevaron a cabo. Como señala David Cohen (2012), Yamashita había ordenado a sus tropas que se retiraran de Manila; sin embargo, lo desobedecieron y se quedaron peleando mientras supuestamente violaban y torturaban sexualmente a unas 30000 mujeres (p. 15). La Comisión concluyó que los delitos sexuales cometidos por las tropas de Yamashita eran tan generalizados y similares, que debieron haber sido "ordenados en secreto o permitidos deliberadamente" (Cohen, 2012, p. 15). ${ }^{13}$ No importó que estos actos no fueran ordenados ni autorizados, porque de todas maneras Yamashita fue encontrado responsable a razón de la responsabilidad del mando. Décadas más tarde, el acusado del TPIY, Radomir Kovač, mantuvo a cuatro jóvenes musulmanas bosnias en su apartamento e invitó a sus amigos a visitarlas y violarlas; finalmente, cambió algunas de estas mujeres como regalos o para comprarlas (Sentencia, Fiscal $c$. Dragoljub Kunarac y otros, párr. 78). ${ }^{14}$ Hace apenas unos años, en el juicio del expresidente de Chad, Hissène Habré, grupos de derechos

12 La Sala de Primera Instancia de las ECCC condenó a ambos acusados de crímenes de lesa humanidad en forma de actos inhumanos de matrimonio forzado y violación en el contexto del matrimonio forzado.

13 Cursivas fuera del original.

14 La condena de Kovač por violación y otros delitos fue confirmada en 2002 por la Sala de Apelaciones del TPIY. 
humanos documentaron la violación rutinaria de detenidos por parte de guardias de la prisión a cambio de medicamentos, alimentos y otras necesidades diarias (Human Rights Watch, 2013, p. 234). Nada de esto fue ordenado ni autorizado; nada de esto obedeció a un objetivo militar específico o parece haber sido una política adoptada a propósito. En cambio, estas prácticas posiblemente se cometieron con la complicidad de los compañeros y fueron toleradas por los mandos. ${ }^{15}$ Los tribunales penales internacionales llevan mucho tiempo procesando la violencia sexual cometida no en cumplimiento de una orden o política oficial, sino por personas o grupos que actúan con un sentido de total impunidad.

\section{La violencia sexual como práctica y análisis de género}

El entender la violencia sexual como una práctica potencial de los actores armados puede mejorar el análisis de género de un determinado conflicto armado o situación de violencia masiva. El Alto Comisionado de la ONU para los Derechos Humanos, describe un análisis de género como una herramienta que ayuda a

reconocer, comprender y visibilizar la naturaleza de género de las violaciones a los derechos humanos, incluyendo su impacto específico y diferencial en mujeres, hombres y otros, así como las violaciones a los derechos humanos basadas en el género, dirigidas específicamente a las personas LGBTI (...) También busca analizar las relaciones de poder dentro de contextos socioculturales, económicos, políticos y ambientales más amplios, para comprender las causas fundamentales de la discriminación y la desigualdad (Oficina del Alto Comisionado de la ONU para los Derechos Humanos, 2018, p. 7). ${ }^{16}$

La realización de ese análisis también se ha convertido en una parte integral de la investigación y el enjuiciamiento de crímenes internacionales. Por ejemplo, en su documento de política de 2014 sobre delitos

15 Estos delitos sexuales contribuyeron a las condenas definitivas de Kovač y Habré por el TPIY y las salas africanas extraordinarias, respectivamente. Ver: Sentencia, Fiscal c. Dragoljub Kunarac y otros; Sentencia, Ministere Public v. Hissein Habre.

16 Traducción propia. 
sexuales y de género, la Fiscalía de la CPI señaló que "la Fiscalía aplicará un análisis de género a todos los delitos dentro de su jurisdicción, examinando cómo esos delitos se relacionan con desigualdades entre mujeres y hombres, y niñas y niños, y las relaciones de poder y otras dinámicas que dan forma a los roles de género en un contexto específico" (Oficinal del Procurador - CPI, p. 5). En 2016, el Fiscal de la CPI emitió las Directrices de análisis de género de la Fiscalía, con instrucciones operativas para las diferentes unidades y fases del proceso.

Un análisis de género puede presentar una imagen más completa acerca de cómo actos aparentemente dispares hacia mujeres y hombres juntos revelan una verdad más amplia de violencia masiva. Por ejemplo, hombres y mujeres pueden ser tratados de manera diferente en el mismo momento de conflicto. Veamos cómo Michelle Jarvis (2016) explica los eventos en Foča en la ex-Yugoslavia de abril de 1992 a enero de 1994, en los que hombres y mujeres bosnios musulmanes fueron tratados de manera diferente: los hombres (y niños) fueron encarcelados ilegalmente y mantenidos en condiciones inhumanas, en tanto que mujeres (y niñas) fueron capturadas, a menudo con fines sexuales (p. 11). Juntos, estos dos esfuerzos dispares y de género demostraron una campaña única y más amplia: la represión y el control de la población musulmana de Bosnia. De manera similar, al dar sentido a la violencia en Srebrenica en 1995, fueron los asesinatos de hombres y las expulsiones de mujeres, niños y ancianos, los que, en conjunto, arrojaron luz sobre la intención más ambiciosa de destruir la comunidad musulmana de Bosnia. Vistas en conjunto, estas formas de daño separadas por género ayudaron a probar el genocidio. ${ }^{17}$

En años más recientes en Kenia, una mirada más profunda a las normas de género locales iluminó el significado detrás de la mutilación genital de varios hombres durante la violencia postelectoral de Kenia (2007-2008). Los hombres atacados eran miembros de la tribu Luo, la única tribu importante en Kenia que tradicionalmente no circuncida a sus varones. Por ser Luos, estos hombres fueron imputados como miembros del partido de oposición, el Movimiento Democrático Naranja (ODM, por sus siglas en inglés), debido a alianzas etnopolíticas de larga data entre

17 Véase, por ejemplo, Sentencia, Fiscal c. Radislav Krstic, párrs. 24-38. 
los Luos y el ODM. Por lo tanto, el análisis de la Fiscalía sobre la violencia postelectoral de Kenia informó su comprensión de la "circuncisión forzada" de hombres Luo como un medio de emasculación individual que contribuyó a un intento más amplio de ejercer dominación étnica y política después de las elecciones presidenciales de 2007.18

La sensibilidad ante la violencia sexual cometida como práctica puede enriquecer el análisis general de género de un conflicto armado. La implementación de la violencia ordenada y autorizada, en particular cuando no hay suficiente control o disciplina, probablemente tenga sus raíces en las mismas normas y actitudes de género que informan el comportamiento desordenado y no autorizado de las tropas. Las normas de género subyacentes sobre sexo, género y poder pueden arrojar luz sobre por qué, si se ordena de manera ambigua "desplazar" una comunidad o "limpiar" un área, las tropas se pueden involucrar en violaciones $u$ otras formas de violencia sexual que no fueron ordenadas o autorizadas. Además, es más probable que cometan estos actos si su experiencia sugiere que los comandantes tolerarán tal comportamiento. Por lo tanto, la atención a las normas de género de los miembros de un grupo armado puede mejorar la detección y comprensión de la violencia sexual que cometen como práctica y política por igual.

\section{La violencia sexual como práctica e investigaciones}

No siempre está claro desde un comienzo que un acto de violencia sexual cometido por miembros de un grupo armado constituya un crimen de guerra, un crimen de lesa humanidad o un acto de genocidio. Al comienzo de una investigación, todo es juego limpio. Es necesario recopilar y analizar información sobre un amplio espectro de daños que ocurren en el área afectada para determinar su importancia legal y su relación con el conflicto o ataque más amplio. Esto incluye actos de

18 Aunque originalmente el Fiscal de la CPI había propuesto que la circuncisión forzada de hombres Luo fuera acusada como crimen de lesa humanidad de "otras formas de violencia sexual", la Sala de Cuestiones Preliminares recategorizó estos actos como crímenes de lesa humanidad de "actos inhumanos" (Situación en la República de Kenia, (ICC-01 / 09-02 / 11), párrs. 24, 32, 33, 63, 69, 74; Decisión sobre la confirmación de los cargos de conformidad con el artículo 61 (7) (a) y (b) del Estatuto de Roma, Fiscal c. Francis Kirimi Muthaura y otros, párr. 260-270 (Casos retirados o cargos no confirmados)). 
violencia sexual aparentemente mundanos y no estratégicos por parte de combatientes, que pueden ser tolerados por los comandantes. Así pues, la idea de la violencia sexual como práctica tiene implicaciones tanto para el enfoque de investigación general en su conjunto, como para la estrategia específica de recolección de pruebas para delitos de naturaleza sexual.

\section{Enfoque general de las investigaciones}

A medida que la investigación de crímenes internacionales madura como campo profesional, se puede apreciar el ajuste gradual pero innegable de cómo abordar mejor el tema de la violencia sexual. A medida que el TPIR y el TPIY iban cerrando sus casos, ambos equipos de acusación publicaron reflexiones sobre su manejo pasado de delitos sexuales y de género. Una "lección aprendida" clave fue considerar la violencia sexual y de género desde el comienzo de cualquier estrategia de investigación, incluyendo verla en forma más abierta, enmarcando su comisión en el contexto más amplio del conflicto general. El documento de mejores prácticas del TPIR aconseja además adoptar un "enfoque basado en el delito" en lugar de un "enfoque basado en objetivos" para "garantizar que se pueda identificar a tantos perpetradores como sea posible y se desarrolle una imagen completa de lo que sucedió" (TPIR, 2014, pp. 28-30). ${ }^{19}$ El hecho de lanzar la red de manera amplia desde el principio puede detectar indicios de violencia sexual como práctica de una multitud de perpetradores. Esto puede revelar más sobre cuáles grupos estaban dónde, haciendo qué y cuándo. Con esta imagen mejorada, los investigadores y fiscales pueden comprender mejor el espectro de la violencia cometida y qué perpetradores y comandantes podrían merecer un examen más detenido. Con el tiempo, algunos de estos actos de violencia sexual "más pequeños" o de menor perfil cometidos como práctica por grupos armados pueden llegar a ser crímenes de guerra, crímenes de lesa humanidad o actos de genocidio.

19 Traducción propia. 
Al intentar probar delitos internacionales de violencia sexual, con frecuencia, los investigadores y fiscales se han basado en el testimonio de víctimas y testigos directos. Esto obedece a una buena razón: los delitos sexuales a menudo no se documentan en papel y las pruebas forenses tradicionales de violación o violencia sexual son difíciles de recopilar y preservar en situaciones de conflicto armado (Gopalan et al., 2016, pp. 150-158). Sin embargo, confiar en el testimonio individual también puede estar plagado de desafíos. Hay obstáculos que existen incluso en tiempos de paz: los sobrevivientes pueden enfrentar barreras sociales y estructurales para denunciar; la policía local puede tener una sensibilización o capacidad insuficiente para entrevistar e investigar, y la prueba de estos crímenes íntimos a menudo depende de una credibilidad de una especie de concurso: "él dijo/ella dijo" (Seelinger \& Freccero, 2015). Los investigadores también consideran la posible retraumatización de las víctimas, obstáculos logísticos y de seguridad relacionados con la búsqueda y participación de testigos, y la obtención de testimonios no contaminados frente a múltiples entrevistas de múltiples grupos que operan en una zona afectada por el conflicto (Wiley, 2012, pp. 373-383).

Por esta razón, los investigadores y fiscales de delitos internacionales han estado explorando con frecuencia creciente el uso de pruebas no basadas en víctimas para establecer delitos de violencia sexual. Por ejemplo, el testimonio de testigos presenciales puede ayudar a corroborar los relatos de las víctimas como en el caso Fiscal c. Vlastimir Dordević del TPIY, en el que el testimonio de un testigo sobre los hechos que rodearon la violación no vista de una joven en el bosque fue aceptado como prueba circunstancial (Gopalan et al., 2016, p. 150). Otros testigos oculares pueden aportar información sobre la naturaleza o sistematización de la violencia, como en el caso contra Hissène Habré, cuando exdetenidos testificaron sobre la violencia sexual sufrida por sus compañeros de prisión. ${ }^{20}$ Aunque se utilizan con poca frecuencia para probar directamente la violencia sexual, los testigos expertos pueden

20 Véase, por ejemplo, Testimonio de Clément Abaifouta, martes 9 de noviembre de 2015, Ministère Public c. Hissein Habré, Sala de Primera Instancia Extraordinaria de África, 30 de mayo de 2016. 
ayudar a reforzar la credibilidad de los testigos, como en el caso Fiscal $c$. Anto Furundžija y otros del TPIY, donde un experto explicó los efectos del trastorno de estrés postraumático en la memoria (Gopalan et al., 2016, p. 152). Las pruebas documentales, que también son utilizadas con poca frecuencia para probar específicamente la violencia sexual, han ayudado, sin embargo, a probar la ocurrencia de violencia sexual, como en los informes organizacionales sobre violaciones de mujeres detenidas, o que un comandante había sido informado (por escrito) de la comisión de casos de delitos de violencia sexual (Gopalan et al., 2016, pp. 155-156). Incluso, las pruebas forenses de violencia sexual, aunque rara vez se han utilizado hasta ahora en casos de delitos internacionales, alguna vez ayudaron a fiscales del TPIY a probar la agresión sexual de dos niñas que habían sido arrojadas a un pozo (Sentencia, Fiscal c. Milan Milutinović y otros, párrs. 645, 688-689, 1224, citados en Gopalan et al., 2016, p. 158). Finalmente, al utilizar evidencia en gran parte de fuente abierta, a menudo informes disponibles públicamente por organizaciones de derechos humanos, los fiscales pueden presentar patrones más amplios de violencia -incluidas formas sexuales- para arrojar luz sobre elementos contextuales de crímenes internacionales o establecer vínculos con acusados de alto nivel. El uso cauteloso de información de fuente abierta autenticada para establecer patrones de violencia puede disminuir la dependencia del testimonio de testigos. Por ejemplo, Xabier Agirre Aranburu (2010) señala el uso de encuestas por muestreo, datos clínicos de instalaciones médicas e informes de noticias públicas para ayudar a identificar patrones de violencia sexual (pp. 618-621).

El hecho de ser conscientes de que la violencia sexual puede ser una práctica frecuente ayuda a ampliar la apertura de esta recopilación de pruebas. Por ejemplo, si se busca comprender si un grupo armado se involucra en violencia sexual como práctica y de qué manera lo hace, las normas sociales entre los miembros de ese grupo armado, en particular las relativas al género, adquieren una gran relevancia. Esto debería impulsar a los investigadores a buscar nuevas fuentes de información de antecedentes. Estos pueden incluir literatura sociológica sobre normas de género en una región de origen o cultura militar específica; datos de salud pública sobre las tasas de violencia de género o explotación 
sexual en el contexto del hogar de un grupo; relatos internos de rituales de reclutamiento y novatadas asociados con un grupo armado, e, incluso, contenido de redes sociales subido por miembros del grupo. $\mathrm{Si}$ bien por lo general la información de antecedentes no se puede utilizar para implicar a personas específicas en delitos específicos, estos datos pueden enriquecer la comprensión de los investigadores sobre las formas de violencia sexual y de género que un grupo puede llevar a cabo y tolerar, incluso más allá de lo ordenado o autorizado. A su vez, esto puede enriquecer el cuestionamiento, el reconocimiento de patrones y la recopilación de pruebas de la "base delictiva".

\section{La violencia sexual como práctica, enjuiciamiento}

Si bien la mayoría de los enjuiciamientos por delitos internacionales, incluidos los de violencia sexual, se han centrado en incidentes cometidos como parte de una "política", también es importante considerar actos sexuales que son tolerados, pero no ordenados ni autorizados, que a menudo están impulsados por dinámicas sociales de pares trasmitidas por normas y jerarquías de género. La exploración de si la violencia sexual ocurrió como práctica puede abrir oportunidades y enfoques de enjuiciamiento ligeramente diferentes. Estos incluyen cómo se imputan los actos subyacentes, la elección del acusado y el tipo de responsabilidad, y el aseguramiento de la posibilidad de enjuiciamiento bajo las leyes penales nacionales.

\section{Caracterización (imputación) de la violencia sexual}

La violencia sexual se puede caracterizar como un crimen internacional implícita o explícitamente en el derecho penal internacional (Sellers, 2008). Implícitamente, los delitos sexuales pueden encubrirse con un lenguaje de acusación eufemístico o ser tratados como daños componentes de delitos más amplios. De manera explícita, los actos sexuales pueden ser enjuiciados directa e independientemente como crímenes de guerra o crímenes de lesa humanidad.

Hemos visto dos formas básicas de enjuiciar implícitamente la violencia sexual como crimen internacional. En primer lugar, durante 
la primera parte del siglo $\mathrm{XX}$, se hizo referencia a la violencia sexual mediante acusaciones redactadas con eufemismos (por ejemplo, el crimen de guerra de "atentados contra la dignidad personal"). ${ }^{21}$ En otras ocasiones, la acusación de delitos sexuales específicos se ha parecido a las muñecas rusas Matrioskas. Es decir, los actos de violencia sexual se han caracterizado como actos componentes internos de un crimen más amplio, que luego se califica como crimen de guerra o de lesa humanidad o como una forma de genocidio, según las circunstancias en las que ocurrió el acto subyacente. Por ejemplo, ante el TPIY y las salas extraordinarias de los tribunales de Camboya, vimos la violación presentada como una forma de tortura, donde la tortura en sí misma fue caracterizada entonces como el crimen general contra la humanidad (Sentencia, Fiscal c. Kunarac y otros; Sentencia, Fiscal c. Kaing Guek Eav, entre otros). De manera similar, como se señaló anteriormente, hemos visto la violación caracterizada como "daño físico o mental grave", un acto constitutivo de genocidio o como el crimen de guerra de "atentados contra la dignidad personal" (Sentencia, Fiscal c. Jean-Paul Akayesu, entre otros). Hemos visto el matrimonio forzado caracterizado como crimen de lesa humanidad de "acto inhumano" (Sentencia, Fiscal c. Alex Tamba Brima y otros, entre otros). En estos escenarios, se prueba el acto directo de violencia sexual (por ejemplo, violación), pero luego se muestra como un componente de un delito más amplio con elementos subjetivos y objetivos específicos (por ejemplo, "Violación como persecución como crimen de lesa humanidad"), o puesto en contexto con otros actos que, en conjunto, comprenden ese delito más amplio (por ejemplo, [violación + detención + asesinato + desplazamiento de un grupo étnico $]=$ persecución como crimen de lesa humanidad). ${ }^{22}$

Los actos de violencia sexual también pueden ser considerados como delitos autónomos cuando así lo disponga el estatuto pertinente. En la década de 1990, los estatutos del TPIY y del TPIR mencionaban específicamente determinadas formas de violencia sexual. Por ejemplo, en el caso

21 Para obtener excelentes discusiones sobre los primeros intentos de enjuiciar los delitos sexuales según el derecho internacional, consulte Cohen (2012) y Askin (2003). Véase también la discusión del trabajo de la Comisión de Crímenes de Guerra de la ONU en apoyo de los enjuiciamientos nacionales después de la Segunda Guerra Mundial por Plesch et al. (2014).

22 Para un resumen detallado del tratamiento de los crímenes de violencia sexual en el TPIY, el TPIR y la SCSL, véase Maystre y Rangel (2012). 
del TPIY, la violación se señala explícitamente como un crimen de lesa humanidad dentro de la jurisdicción del tribunal (Estatuto enmendado TPIY, artículo 5). De manera similar, en el estatuto que establece el TPIR, la lista del artículo 3 de posibles crímenes de lesa humanidad incluye la violación (Estatuto enmendado TPIR, artículo 3). La enumeración legal más amplia de delitos sexuales específicos apareció en el Estatuto de Roma de la CPI, que enumeró no solo la violación sino también la esclavitud sexual, la prostitución forzada, el embarazo forzado y la esterilización forzada como crímenes de lesa humanidad y de guerra. ${ }^{23}$

Además, tipifica como crimen de lesa humanidad "cualquier otra forma de violencia sexual" de gravedad comparable y, cuando constituye una violación grave de los Convenios de Ginebra, es un crimen de guerra (Estatuto de Roma, artículo 8, 2, b, xxiii). La "lista" de delitos sexuales del Estatuto de Roma ha influido en la legislación nacional de los países signatarios, así como en los tribunales híbridos. En los casos en que existan tales disposiciones independientes, estos actos sexuales pueden ser enjuiciados de forma independiente como delitos subyacentes que, si se demuestra que cumplen con los elementos contextuales pertinentes, pueden constituir directamente crímenes de lesa humanidad, de guerra o actos de genocidio.

La violencia sexual que se produce como práctica ha sido imputada y procesada de todas estas formas. Los casos conjuntos del TPIY de Kunarac, Kovač y Vuković constituyen un ejemplo útil. Aquí, el tribunal de primera instancia consideró amplios sistemas de detención y violación de mujeres musulmanas en varios edificios alrededor de Foča. Además de tener conocimiento y participación en ese sistema de violencia, los tres acusados también habían facilitado y participado en violencia sexual "fuera del sitio". Kovač, en particular, había sacado a cuatro mujeres de los lugares de detención y las había mantenido en un apartamento, obligándolas a realizar tareas domésticas, bailar desnudas y tener relaciones sexuales con él y sus compañeros soldados. Finalmente, vendió a algunas de ellas como si fueran propiedad (Fiscal vs. Dragoljub Kunarac y otros). Estos crímenes "fuera del sitio" fueron acusados tanto directamente -por ejemplo, violación como crimen

23 Estatuto de Roma, artículo 7; Primera Convención de Ginebra; Segunda Convención de Ginebra; Tercera Convención de Ginebra; Cuarta Convención de Ginebra. 
de guerra y crimen de lesa humanidad- como crímenes más amplios - por ejemplo, tortura como crimen de guerra y de lesa humanidad; esclavitud como crimen de lesa humanidad, y ultrajes a la dignidad personal como crimen de guerra-. Estos actos, ${ }^{24}$ sin importar cómo se caracterizaron, fueron cometidos no de conformidad con una estrategia o política organizacional específica, sino que fueron permitidos por unos pocos individuos específicos mientras que muchos otros los toleraron, e incluso los disfrutaron. En el reciente caso Fiscal c. Bosco Ntaganda, la Sala de Primera Instancia de la CPI consideró si los presuntos actos de violencia sexual cometidos por sus soldados cumplían con el requisito de "coerción" para la violación como crimen de guerra o de lesa humanidad. Esta sala la encontró afirmativa, señalando las veces que los soldados se habían apoderado de y ocupado aldeas, creando un "ambiente coercitivo" en el que convocaron a niñas de la vía a tener relaciones sexuales. Estas violaciones ocurrieron después de ataques a las aldeas y cuando los soldados estaban en reposo, por ello pueden describirse como práctica de violencia sexual.

Asimismo, la violencia sexual cometida como práctica puede caracterizarse como una forma de persecución, que a su vez puede constituir un crimen de lesa humanidad ante determinados tribunales. En términos de elementos subjetivos y objetivos, la persecución generalmente requiere alguna privación o violación de los derechos humanos fundamentales, motivada por la identidad política, racial, nacional, étnica o religiosa de una persona o grupo. En particular, el Estatuto de Roma también incluye la persecución por motivos de género (artículo 7, 1 y h). Por lo tanto, los actos de violencia sexual no ordenados ni tolerados podrían constituir persecución si el autor directo tenía el estado mental requerido para la persecución, es decir, la intención de dañar a la víctima basándose en al menos uno de los motivos prohibidos. Luego, tomados solos o en combinación con otros comportamientos persecutorios, se puede demostrar que estos actos sexuales cumplen con los requisitos

24 Ha habido cierto debate sobre si los delitos de violencia sexual deben incorporarse a delitos más amplios o si deben ser acusados y procesados en sí mismos. Tras reflexionar sobre las mejores prácticas, los fiscales del TPIY señalan que existen razones importantes para caracterizar los delitos sexuales en ambos sentidos, según el caso y el acusado en cuestión (Baig et al., 2016). 
contextuales más amplios de un crimen de guerra o lesa humanidad. De esta manera, esa instancia de mera práctica puede caracterizarse como (parte de) un acto de persecución como crimen de guerra o lesa humanidad. Este fue el caso en Fiscal c. Miroslav Kvočka y otros del TPIY, en el que cinco hombres fueron condenados por persecución como crimen de lesa humanidad: estuvieron implicados en la persecución de no serbios detenidos en el infame campo de Omarska, que incluyó la violación de presos por motivos políticos, raciales o religiosos.

\section{Elección de acusados y modalidades de responsabilidad}

La atención a la violencia sexual como práctica puede ampliar las opciones sobre a quién acusar y cómo caracterizar su responsabilidad. Primero, la evidencia de violencia sexual como práctica de miembros de un grupo armado puede indicar en dónde se permitió o, incluso, se alentó a ciertas unidades a abusar. Esto, a su vez, puede promover la acusación de los perpetradores directos y sus comandantes más inmediatos. Si bien los tribunales internacionales se han centrado en gran medida en los comandantes de más alto nivel, debido a los esfuerzos de los tribunales para juzgar a los "más responsables" de las atrocidades, también han considerado a los actores de niveles medio y bajo, incluso cuando su enjuiciamiento podría ayudar a construir casos contra los de mayor mando (Oficina del Fiscal, CPI, 2014, p. 5). La consideración de la violencia sexual cometida como una práctica puede ayudar a vincular a quienes cometen violencia sobre el terreno a través de los distintos niveles de mando por encima de ellos. Esto puede ser prudente a la luz de la sentencia de apelación de 2018 en el caso de la CPI Fiscal c. Jean-Pierre Bemba Gombo, que se analiza a continuación, que parece favorecer de manera controvertida una relación más cercana y próxima entre el comandante y el subordinado para demostrar la responsabilidad del mando. La lógica de la Sala de Apelaciones parece indicar que la Fiscalía de la CPI podría haber tenido más éxito si hubiera incluido comandantes de menor rango y más implicados localmente. ${ }^{25}$

25 La decisión de la Apelación Bemba ha sido debatida enérgicamente por varios expertos, incluidos Leila Sadat, Diane Amman y Michael Newton en el ICC Forum (Amman et al., 2019) y Alex Whiting (2018). 
En segundo lugar, el tema relacionado de las modalidades de responsabilidad o cómo etiquetar la violencia sexual cometida como práctica podría implicar determinadas formas de responsabilidad más que otras. Los miembros de la Fiscalía del TPIY han reflexionado sobre las dificultades que frecuentemente experimentan al intentar conectar un acto sexual específico con una estrategia o política militar más amplia. Señalaron el valor de avanzar hacia un análisis más contextual, incluso si los delitos sexuales ocurrieron como una práctica tolerada por los superiores (Wood, 2014; Baig et al., 2016, pp. 172-173, 217). Tales situaciones resaltan la relevancia de los modos de responsabilidad basados en ciertas circunstancias: roles de complicidad o apoyo, la "omisión" de algún deber afirmativo y la acción a pesar de alguna consecuencia "previsible".

\section{Responsabilidad de mando o superior}

Un aspecto relevante de la responsabilidad es el incumplimiento de algún deber de actuar, más específicamente, prevenir, controlar y sancionar. Una forma primaria de "responsabilidad por omisión" es la responsabilidad de mando o superior. Según esta teoría, los superiores son considerados responsables de los actos de sus subordinados. Su aplicación generalmente requiere la demostración de la existencia de una relación subordinado-superior que implica un "control efectivo" del primero sobre el segundo; el conocimiento del superior de que el o los subordinados iban a cometer o habían cometido el delito, y si ese comandante tomó todas las medidas necesarias y razonables para prevenir o sancionar el acto delictivo (Goy et al., 2016, p. 241). ${ }^{26}$ Este principio de responsabilidad se ha expresado en varios casos de violencia sexual relacionada con conflicto, que se remontan al menos al juicio antes mencionado de Peter von Hagenbach en 1474. Más recientemente, el caso Fiscal v. Zejnil Delalic y otros del TPIY resultó en la condena de un comandante de facto del campo de prisioneros de Celibici, donde guardias subordinados abusaron sexualmente de los detenidos. También fue una base de responsabilidad subyacente a la condena inicial

26 Véase, por ejemplo, Sentencia, Fiscal c. Alex Tamba Brima y otros (SCSL-04-16-T), Sala de Primera Instancia de la SCSL, 20 de junio de 2007, párrs. 721-32. 
de Jean-Pierre Bemba Gombo por la Sala de Primera Instancia de la CPI en 2016, cuando Bemba, un líder de alto rango del Mouvement de Libération du Congo (MLC) de la República Democrática del Congo fue declarado culpable de delitos sexuales cometidos por tropas del MLC estacionadas en la República Centroafricana (Fiscal c. Jean-Pierre Bemba Gombo). Sin embargo, la condena fue anulada por una controvertida sentencia de apelación en junio de 2018.

Una corte dividida finalmente concluyó, entre otras cosas, que la Sala de Primera Instancia se había equivocado en su evaluación de las medidas que Bemba podría haber tomado de manera realista para controlar y castigar a las tropas distantes del MLC por los delitos (incluidos los sexuales) que habían cometido en la República Centroafricana. Aunque ajenos a la decisión, los jueces Van der Wyngaert y Morrison también señalaron en una Opinión Separada muy criticada, que los diferentes individuos en la cadena de mando tienen diferentes grados de responsabilidad por las acciones de las tropas de los niveles más bajos, y los supervisores inmediatos tienen una responsabilidad significativamente mayor que los superiores distantes (Opinión Separada, Fiscal c. Jean-Pierre Bemba Gombo, párrs. 33-34).

Por controvertida que sea la decisión del caso Bemba, en principio no afecta el enjuiciamiento de la violencia sexual como práctica: la violencia sexual como práctica no es distinta de la violencia sexual estratégica en cuanto a fines de responsabilidad de mando, que no asume en absoluto la comisión directa o la intención penal del comandante. La Opinión Separada de Bemba señala que, si bien por lo general los comandantes solo deben ser considerados responsables cuando sabían que subordinados específicos estaban "a punto de" cometer delitos, aún podrían haber estado en aviso efectivo ("deberían haber sabido") cuando el comandante tiene conocimiento de un patrón pasado de conducta criminal entre ciertas tropas (párr. 45). Presumiblemente, esto podría incluir el conocimiento de la práctica frecuente de violencia sexual por parte de las tropas.

\section{Ayudar e incitar}

Debido a las dimensiones altamente sociales de la violencia sexual como práctica, a menudo existe cierto grado de complicidad entre 
pares. Esta puede venir en forma de "complicidad", que generalmente incluye brindar "asistencia práctica, aliento o apoyo moral" al perpetrador principal (Fiscal c. Anto Furundžija y otros, párrs.235 y 249). El TPIY ha señalado que, incluso la mera presencia de un acusado en la escena de un crimen puede desencadenar responsabilidad compartida cuando se demuestra que su presencia "tiene un efecto alentador significativo sobre el delincuente principal" (Sentencia, Fiscal c. Mitar Vasiljevic, párrs. 70-71). Esta fue la situación en el caso Furundžija del TPIY, en el que el acusado fue declarado culpable de complicidad e incitación a la violencia sexual porque estaba presente para observar y comunicó tácitamente su apoyo al interrogatorio de otro soldado y la violación del testigo. Por lo general, el estado mental requerido para "ayudar e incitar" es simplemente la conciencia de que los propios actos $u$ omisiones de alguna manera ayudan en la comisión del delito específico por parte del delincuente principal (Fiscal c. Mitar Vasiljevic, párr. 71). Como uno podría imaginar, en los casos de violencia sexual cometidos como práctica, esto podría incluir la presión de los compañeros de tropa, o la tolerancia (aunque reacia) de los comandantes. Este modo de responsabilidad también puede ser relevante cuando los acusados no castigan la violencia sexual como práctica, creando un ambiente de impunidad.

\section{Asociación para delinquir III y propósito común}

Prestar atención a la violencia sexual como práctica durante una investigación puede iluminar patrones de comportamiento entre los miembros de un grupo armado, lo que a su vez puede demostrar la probabilidad o previsibilidad de su comisión. En este sentido, la tercera forma de "asociación para delinquir" (JCE-III) ha sido históricamente relevante. Esta gira en torno a la idea de previsibilidad, atribuyendo responsabilidad penal cuando, en el contexto de un diseño común para seguir un curso específico de conducta, "uno de los perpetradores comete un acto que, aunque fuera del diseño común, fue sin embargo una consecuencia natural y previsible del cumplimiento de ese propósito común" (Sentencia de Apelación, Fiscal c. Dusko Tadic, párr. 204). El artículo 25 del Estatuto de Roma de la CPI establece una forma similar de responsabilidad penal individual cuando una persona contribuye 
intencionalmente a la comisión o intento de comisión de un delito por un grupo de personas que actúan con un "propósito común". Además, el artículo 30 describe los requisitos generales del Estatuto de Roma en cuanto al estado mental, que incluyen la conciencia de que ocurrirán ciertas consecuencias, como por ejemplo, la violencia sexual "en el curso normal de los acontecimientos". Esto sugiere la relevancia de la información o la experiencia relacionada con las tendencias de un grupo armado hacia la violencia sexual, lo que puede indicar la previsibilidad de su comisión.

El caso Katanga de la CPI ilustra cómo la evidencia de delitos sexuales como práctica puede ser relevante para la previsibilidad. Al determinar si aceptar cargos de violación y esclavitud sexual en el caso, la mayoría de los jueces de la Sala de Cuestiones Preliminares encontraron la existencia de un plan común para "arrasar" la aldea de Bogoro (Decisión sobre Confirmación de Cargos, Fiscal c. Germain Katanga y Mathieu Ngudjolo Chui, párr. 549). Además, encontraron "pruebas suficientes para establecer motivos fundados para creer que, en el curso ordinario de los acontecimientos, la aplicación del plan común inevitablemente resultaría en la violación o esclavitud sexual de mujeres civiles" en Bogoro en la República Democrática del Congo (Decisión sobre Confirmación de Cargos, Fiscal c. Germain Katanga y Mathieu Ngudjolo Chui, párr. 568). La mayoría señaló, entre otras cosas, que la violación y la esclavitud sexual de mujeres y niñas constituían una práctica común en la región de Ituri durante todo el conflicto armado. Esta práctica común fue ampliamente reconocida entre soldados y comandantes, los combatientes eran entrenados y crecieron en campamentos en los que mujeres y niñas eran constantemente violadas y sometidas a esclavitud sexual. El destino reservado para las mujeres y niñas capturadas era ampliamente conocido entre los combatientes, tanto los sospechosos como combatientes sabían qué campamentos y qué comandantes participaban con mayor frecuencia en esta práctica (Decisión sobre Confirmación de Cargos, Fiscal c. Germain Katanga y Mathieu Ngudjolo Chui, párr. 568)

Katanga fue finalmente absuelto de estos cargos porque la Sala de Primera Instancia no encontró pruebas suficientes de su responsabilidad personal por las violaciones cometidas por sus subordinados (Sentencia, Fiscal c. Germain Katanga). Es posible que el conjunto de violaciones en 
cuestión fuera demasiado pequeño y específico; la demostración de su participación en un sistema más amplio de tolerancia de la violencia sexual como práctica podría haber tenido más éxito.

Los jueces de las salas africanas extraordinarias de Senegal también examinaron la previsibilidad de la violación y la esclavitud sexual durante el juicio de 2015-2016 de Hissène Habré, expresidente de Chad. En el caso Habré, las pruebas indicaron que mujeres y niños eran violados habitualmente durante su detención por guardias que les retenían alimentos y medicinas hasta que les proporcionaran servicios sexuales. Las pruebas también demostraron que, por orden de Habré, las mujeres eran enviadas a campamentos militares en el desierto para servir como trabajadoras domésticas para los soldados. Estas mujeres eran violadas y obligadas a la esclavitud de forma rutinaria, lo que implicaba violencia sexual. Los jueces de instrucción concluyeron que, dada la detención de mujeres en una prisión con personal exclusivamente masculino y el estrecho control de Habré sobre esas prisiones, la violación debería haber sido previsible, especialmente a la luz de las alarmas planteadas por grupos internacionales de derechos humanos. De manera similar, al evaluar la decisión de Habré de enviar mujeres a los campamentos militares, la sala de instrucción señaló específicamente el aislamiento extremo de los campamentos del desierto, la situación vulnerable de las mujeres desplazadas y el hecho de que la gran mayoría de los soldados estacionados allí estaban lejos de sus cónyuges (Sentencia, Ministère Public c. Hissein Habré, párrs. 2157-2170) encontró que en ese entorno la violación y la esclavitud sexual deberían haber sido previsibles. Estos hallazgos contribuyeron a la condena de Habré por violación y esclavitud sexual como crímenes de lesa humanidad, incluso sobre la base de responsabilidad de la JCE-III. ${ }^{27}$

\section{Opciones de responsabilidad}

La violencia sexual cometida como práctica también puede ser valiosa de otras dos formas. En primer lugar, delitos sexuales que en última instancia pueden no cumplir con los elementos contextuales de

27 Habré también fue declarado responsable bajo otros modos de responsabilidad, incluida la JCE-II y la responsabilidad del mando. 
los crímenes de guerra o contra la humanidad, o los actos de genocidio, aún pueden ser imputados y enjuiciados como crímenes en virtud de las leyes penales nacionales. Si bien se pierde el valor expresivo del derecho penal internacional (van Schaack, 2008), la imputación alternativa de delitos sexuales en virtud de las disposiciones del derecho penal ordinario puede ofrecer una oportunidad para rendición de cuentas. Un ejemplo vivo de esta estrategia se puede encontrar en Uganda. En el momento de redactar este informe, el excomandante del Ejército de Resistencia del Señor, Thomas Kwoyelo, se encuentra ante la División de Delitos Internacionales del Tribunal Superior de Uganda, donde está acusado de 93 cargos de derecho penal internacional, incluyendo cargos de violencia sexual, junto con cargos alternativos según las disposiciones de la legislación penal nacional. ${ }^{28}$

Además, el captar el espectro completo de la violencia sexual, ya sea que constituya un delito bajo cualquier marco legal, puede ser un componente crucial de otros esfuerzos relacionados con la rendición de cuentas, como las comisiones de investigación y esfuerzos más amplios de documentación de derechos humanos. La investigación y documentación de la violencia sexual en conflictos armados y crisis humanitarias, incluyendo actos que puedan ser cometidos casualmente por actores armados, son esenciales para documentar, además de determinar posibles cargos por esfuerzos relacionados con la justicia. Por ejemplo, los informes exhaustivos de investigación de la Comisión de Derechos Humanos de la ONU en Sudán del Sur y la Comisión de Investigación de Derechos Humanos de la ONU en Eritrea, proporcionaron una gran comprensión de un espectro de violencia sexual perpetrada en esas dos áreas afectadas por conflictos, incluyendo detalles de violaciones desenfrenadas y no ordenadas y servidumbre doméstica (sexual), cometidas por actores civiles y armados por igual (Asamblea General, ONU, 2016, párrs. 48-49; Consejo de Derechos Humanos, ONU, 2020). Sin duda, esos informes pueden servir de base para un futuro enjuiciamiento, pero lo que es más importante, guían a los legisladores en decisiones

28 Acusación Formal Enmendada, Fiscal c. Kwoyelo Thomas alias Latoni (Caso No. 02 de 2010), División de Crímenes Internacionales del Tribunal Superior de Uganda en Kampala, 2017. En posesión del autor. Cargos confirmados el 30 de agosto de 2018. 
relacionadas con la prevención, el apoyo y la protección. Por tanto, la documentación de la violencia sexual como práctica es fundamental.

\section{Conclusión}

En este texto argumentamos que actores armados pueden participar en actos de violencia sexual sin que esta haya sido adoptada intencionalmente en algún nivel de mando como política organizacional en general o como estrategia militar en particular. Cuando la violencia sexual es frecuente como práctica, se rige por normas y jerarquías de género entre los combatientes y es tolerada por al menos algunos comandantes. No hay duda de que la violación y otras formas de violencia sexual son adoptadas como política por algunas organizaciones armadas, incluso como estrategia militar. Enfatizamos que la violencia sexual como política puede estar autorizada, mas no ordenada por los comandantes.

Después de establecer que los delitos sexuales que ocurren como práctica a menudo son calificados como delitos internacionales fundamentales, analizamos las implicaciones para la investigación y el enjuiciamiento. El hecho de que la violencia sexual como práctica refleje normas y jerarquías de género tanto de combatientes como de comandantes refuerza la importancia de investigar las dinámicas de género dentro, de las organizaciones armadas. La investigación y el enjuiciamiento informados mediante un análisis de género atento a estas dinámicas pueden iluminar el contexto de los crímenes internacionales, el significado de los daños infligidos y las dinámicas de género que impulsan su ocurrencia y tolerancia.

Más específicamente, nuestro análisis refuerza el énfasis de las recientes mejores prácticas en la investigación del espectro completo de los delitos de violencia sexual, incluyendo la atención dirigida a la posibilidad de que algunos puedan ocurrir como práctica, además de la posibilidad de que ocurran como política de la organización o quizás como estrategia militar. En particular, hicimos énfasis en la importancia de documentar las dinámicas sociales de género entre los combatientes, así como de reunir pruebas de la tolerancia de los comandantes. 
Argumentamos que la violencia sexual que ocurre como práctica puede ser acusada y enjuiciada en una amplia variedad de formas, incluso como delitos independientes, actos subyacentes que contribuyen o constituyen delitos más amplios o también como delitos bajo el derecho penal nacional en el caso que los elementos contextuales de los principales crímenes internacionales podrían no cumplirse plenamente. Enfatizamos que cuando la violación ocurre como práctica, los patrones de comportamiento pueden ser detectables, haciendo que estos crímenes sean previsibles para comandantes y colaboradores. Al menos tres aspectos de la responsabilidad están claramente implicados: complicidad o apoyo; omisión de algún deber afirmativo de prevenir o sancionar, y acción a pesar de las consecuencias previsibles. Por lo tanto, la violencia sexual como práctica implica ciertos modos de responsabilidad más que otros. Sugerimos que la ayuda y complicidad, la responsabilidad de mando/superior, la asociación para delinquir y el propósito común son de particular relevancia. Al hacer seguimiento a las implicaciones del análisis reciente de las ciencias sociales sobre la violencia sexual durante la guerra, esperamos que nuestro análisis lleve a una mayor responsabilidad de líderes y combatientes, así como a pasos encaminados a su prevención.

\section{Referencias}

Agirre Aranburu, X. (2010). Sexual violence beyond a reasonable doubt: Using pattern evidence and analysis for international cases. Leiden Journal of International Law, 23(3), 609-627.

Amman, D. M., Jackson, M., Newton, M., Poutou, N. C. F., E Sadat, L. N. (2019). Invited experts on responsibility question. ICC Forum. https:// iccforum.com/responsibility

Askin, K. D. (2003). Prosecuting wartime rape and other gender-related crimes under international law: Extraordinary advances, enduring obstacles. Berkeley Journal of International Law, 21(2), 288-349.

Askin, K. D. (2004). A decade of the development of gender crimes in international courts and tribunals: 1993 to 2003. Human Rights Brief, 11(3), 16-19. 
Baig, L., Jarvis, M., Salgado, E. M., \& Pinzauti, G. (2016). Contextualizing Sexual Violence: Selection of Crimes. En S. Brammertz, \& M. Jarvis (Eds.), Prosecuting conflict-related sexual violence at the ICTY (pp. 172-219). Oxford University Press.

Boesten, J. (2010). Analyzing rape regimes at the interface of war and peace in Peru. The International Journal of Transitional Justice, 4(1), 110-129.

Boesten, J. (2017). Of exceptions and continuities: Theory and methodology in research on conflict-related sexual violence. International Feminist Journal of Politics, 19(4), 506-519.

Brownmiller, S. (1975). Against our will: Men, women and rape. Ballantine.

Butler, C. K., Gluch, T., E Mitchell, N. J. (2007). Security forces and sexual violence: A cross-national analysis of a principal-Agent argument. Journal of Peace Research, 44(6), 669-687.

Cockburn, C. (2004). The continuum of violence: A gender perspective on war and peace. En W. Giles, \& J. Hyndman (Eds.), Sites of violence: Gender and conflict zones (pp. 24-44). University of California Press.

Cohen, D. (2012). Prosecuting sexual violence from Tokyo to the ICC. En M. Bergsmo, A. B. Skre, \& E. J. Wood (Eds.), Understanding and proving international sex crimes (pp. 13-64). FICHL Torkel Opsahl Academic EPublisher.

Cohen, D. K. (2013a). Female combatants and violence in armed groups: Women and wartime rape in Sierra Leone. World Politics, 65(3), 383-415. Cohen, D. K. (2013b). Explaining rape during civil war: Cross-national evidence (1980-2009). American Political Science Review, 107(3), 461-477.

Cohen, D. K. (2016). Rape during civil war. Cornell University Press.

Cohen, D. K., E Nordås, R. (2014). Sexual violence in armed conflict: Introducing the SVAC dataset, 1989-2009. Journal of Peace Research, 51(3), 418-428.

Corte Penal Internacional, Oficina del Procurador. Documento de politicas y crímenes sexuales y por motivos de género. https://www.icc-cpi.int/iccdocs/ otp/PolicyPaperOnSexualAndGender-BasedCrimesSpa.pdf

Eriksson Baaz, M., \& Stern, M. (2009). Why do soldiers rape? Masculinity, violence, and sexuality in the armed forces in the Congo (DRC). International Studies Quarterly, 53(2), 495-518.

Eriksson Baaz, M., E Stern, M. (2013). Sexual violence as a weapon of war? Perceptions, prescription, problems in the Congo and beyond. Zed Books.

Gopalan, P., Kravetz, D., G Menon, A. (2016). Proving crimes of sexual violence. En S. Brammertz, \& M. Jarvis (Eds.), Prosecuting conflict-related sexual violence at the ICTY (pp. 111-171). Oxford University Press. 
Goy, B., Jarvis, M., E Pinzauti, G. Contextualizing sexual violence and linking it to senior officials: Modes of liability. En S. Brammertz, E M. Jarvis (Eds.), Prosecuting conflict-related sexual violence at the ICTY (pp. 220-261). Oxford University Press.

Gutiérrez-Sanín, F., E Wood, E. J. (2020). Cómo debemos entender el concepto de "patrón de violencia política": repertorio, objetivo, frecuencia y técnica. Estudios Socio-Jurídicos, 22(2), 13-65.

Hoover Green, A. (2016). The commander's dilemma: Creating and controlling armed group violence. Journal of Peace Research, 53(5), 619-632.

Hoover Green, A. (2018) The commander's dilemma: Violence and restraint in wartime. Cornell University Press.

Human Rights Watch. (2013). La plaine des morts. Le Tchad de Hissène Habré 1982-1990. https://www.hrw.org/sites/default/files/reports/chad1013frwebwcover_0.pdf

Jarvis, M. (2016). Overview: The challenge of accountability for conflict-related sexual violence crimes. En S. Brammertz, \& M. Jarvis (Eds.), Prosecuting conflict-related sexual violence at the ICTY (PP. 1-18). Oxford University Press.

Maystre, M., E Rangel, N. (2012). Analytical and comparative digest of ICTY, ICTR and SCSL jurisprudence on international sex crimes. En: M. Bergsmo, A. B. Skre, E E. J. Wood (Eds.), Understanding and proving international sex crimes (pp. 511-878). FICHL Torkel Opsahl Academic EPublisher.

Meger, S. (2016) Rape loot pillage: The political economy of sexual violence in armed conflict. Oxford University Press.

ONU, Asamblea General. (22 de abril de 2016). Misión de evaluación de la Oficina del Alto Comisionado de las Naciones Unidas para los Derechos Humanos para mejorar la situación en materia de derechos humanos, rendición de cuentas, reconciliación y capacidad en Sudán del Sur. Informe del Alto Comisionado de las Naciones Unidas para los Derechos Humanos.

ONU, Asamblea General. (9 de mayo de 2016). Informe de la comisión de investigación sobre los derechos humanos en Eritrea. https://documents-dds-ny.un.org/doc/UNDOC/GEN/G16/093/45/PDF/G1609345. pdf?OpenElement

ONU, Consejo de Derechos Humanos. (2020). Comisión de Derechos Humanos para Sudán del Sur. https://www.ohchr.org/EN/HRBodies/HRC/CoHSouthSudan/Pages/Index.aspx

ONU, Consejo de Seguridad. (29 de marzo de 2019). Violencia sexual relacionada con los conflictos. Informe del Secretario General, S/2019/280. https://www. un.org/sexualviolenceinconflict/wp-content/uploads/2019/12/report/ 
violencia-sexual-relacionada-con-los-conflictos-informe-del-secretariogeneral-s-2019-280-spanish/ESP.pdf

ONU, Oficina del Alto Comisionado para los Derechos Humanos. Integrating a gender perspective into human rights investigations. Guidance and practice. https://www.ohchr.org/Documents/Issues/Women/Publications/GenderIntegrationintoHRInvestigations.pdf

Osiel, M. J. (1998). Obeying orders: Atrocity, military discipline, and the law of war. California Law Review, 86, 939-1129.

Peers, W. R. (1979). The My Lai inquiry. Norton.

Plesch, D., Sácouto, S., E Lasco, C. (2014). The relevance of the United Nations War Crimes Commission to the prosecution of sexual and gender-based crimes today. Criminal Law Forum, 25(1-2), 349-381.

Richardot, S. (2014). 'You know what to do with them': The formulation of orders and engagement in war crimes. Aggression and Violent Behavior, 19(2), 83-90.

Seelinger, K.T., \& Freccero, J. (2015). The long road: Accountability for sexual violence in conflict and post-conflict settings. https://www.law.berkeley.edu/ wpcontent/uploads/2015/04/The-Long-Road-August-2015.pdf

Sellers, P. V. (2008). The prosecution of sexual violence in conflict: The importance of human rights as means of interpretation. https://www.un.org/ruleoflaw/blog/ document/the-prosecution-of-sexual-violence-in-conflict-theimportanceof-human-rights-as-means-of-interpretation/

Sjoberg, L. (2016). Women as wartime rapists: Beyond sensation and stereotyping. New York University Press.

Van Schaack, B. (2008). Crimen sine lege: Judicial lawmaking at the intersection of law and morals. Georgetown Law Journal, 97(119), 121-122.

Tribunal Penal Internacional para Ruanda. (2014). Prosecution on sexual violence. Best practices manual for the investigation and prosecution of sexual violence crimes in post-conflict regions: Lessons learned from the Office of the Prosecutor of the International Criminal Tribunal for Ruanda. https://unictr.irmct.org/sites/ unictr.org/files/legal-library/140130_prosecution_of_sexual_violence.pdf Weaver, G. (2010) Ideologies of forgetting: Rape in the Vietnam War. State University of New York Press.

Whiting, A. (14 de junio de 2018). Appeals judges turn the ICC on its head with Bemba decision. Just Security. https://www.justsecurity.org/57760/ appeals-judges-turn-icchead-bemba-decision/

Wiley, W. H. (2012). The difficulties inherent in the investigation of allegations of rape before international courts and tribunals. En M. Bergsmo, A. B. 
Skre, E E. J. Wood (Eds.) Understanding and proving international sex crimes (pp. 367-388). FICHL Torkel Opsahl Academic EPublisher.

Winslow, D. (1999). Rites of passage and group bonding in the Canadian airborne. Armed Forces \& Society, 25(3), 429-457.

Wood, E. J. (2006). Variation in sexual violence during war. Politics and Society, 34(3), 307-342.

Wood, E. J. (2009). Armed groups and sexual violence: When is wartime rape rare?" Politics and Society, 37(1), 131-161.

Wood, E. J. (2012). Rape during war is not inevitable: Variation in wartime sexual violence. En M. Bergsmo, A. B. Skre, E E. J. Wood (Eds.), Understanding and proving international sex crimes (pp. 389-419). Torkel Opsahl Academic Epublisher.

Wood, E. J. (2014). Conflict-related sexual violence and the policy implications of recent research. International Review of the Red Cross, 96(894), 457-478.

Wood, E. J. (2018). Rape as a practice of war: Toward a typology of political violence." Politics \& Society, 46(4), 513-537.

Wood, E. J., E Bleckner, J. (2017). Conflict-related sexual violence. Armed Conflict Survey, 25-38.

\section{Jurisprudencia}

Prosecutor v. Dragoljub Kunarac et al. (IT-96-23-T), ICTY Trial Chamber, 22 February 2001.

Prosecutor v. Dragoljub Kunarac et al (IT-96-23 \& IT-96-23/1-A) ICTY Appeals Chamber, 12 June 2002.

Prosecutor v. Dusko Tadic (IT-94-1-A) ICTY Appeals Chamber, 15 July 1999.

Prosecutor v. Radovan Karadzic (IT-95-5/18-AR98bis.1), Appeals Chamber, 11 July 2013.

Prosecutor v. Radislav Krstic (IT-98-33-A), ICTY Appeal Chamber, 19 April 2004.

Prosecutor v. Milan Milutinović et al. (IT-05-87-T), ICTY Trial Chamber, 26 February 2009.

Prosecutor v. Miroslav Kvocka et al. (IT-98-30/I-T), ICTY Trial Chamber, 2 November 2001.

Prosecutor v. Zejnil Delalic et al. (IT-96-21-T), ICTY Trial Chamber, 16 November 1998.

Prosecutor v. Anto Furundžija et al. ("Celibici case")(IT-95-17/1-T), ICTY Trial Chamber, 10 December 1998. 
Prosecutor v. Anto Furundžija (IT-95-17/1-A), ICTY Appeals Chamber, 21 July 2000. Prosecutor v. Mitar Vasiljevic (IT-98-32-T), ICTY Trial Chamber, 29 November 2002.

International Criminal Tribunal for Ruanda (ICTR).

Prosecutor v. Jean-Paul Akayesu (ICTR-96-4-T) ICTR Trial Chamber, 2 September 1998.

Prosecutor v. Alex Tamba Brima et al (SCSL-04-16-A) SCSL Appeals Chamber, 22 February 2008.

Prosecutor v. Alex Tamba Brima et al (SCSL-04-16-T), SCSL Trial Chamber, 20 June 2007.

Prosecutor v. Athanase Seromba (ICTR-2001-66-A), Appeals Chamber, 12 March 2008.

Extraordinary Chambers in the Courts of Cambodia (ECCC).

Prosecutor v. Kaing Guek Eav (001/18-07-2007/ECCC/TC), ECCC Trial Chamber, 26 July 2010.

Prosecutor v. Nuon Chea and Khieu Samphan (Case file no. 002/19-09-2007/ ECCC/TC), 16 November 2018 International Criminal Court (ICC).

Prosecutor v. Katanga and Chui (ICC-01/04-01/07), ICC Pre-Trial Chamber, 30 September 2008.

Prosecutor v. Germain Katanga and Mathieu Ngudjolo Chui (ICC-01/04-01/07), ICC Pre-Trial Chamber, 30 September 2008.

Prosecutor v. Germain Katanga (ICC-01/04-01/07), ICC Trial Chamber, 7 March 2014.

Situation in the Republic of Kenya, (ICC-01/09-02/11) ICC Pre-trial Chamber II, 19 August 2011.

Prosecutor v. Francis Kirimi Muthaura et al, (ICC-01/09/02) ICC Pre-trial Chamber, 23 January 2012.

Prosecutorv. Jean-Pierre Bemba Gombo (ICC-01/05-01/13), ICC Appeals Chamber, 8 March 2018.

Prosecutor v. Jean-Pierre Bemba Gombo (ICC-01 / 05-01 / 08-3636-Anx2 0806-2018 1/34 EC A), ICC Appeals Chamber, 8 June 2018.

Prosecutor v. Bosco Ntaganda (ICC-01-04-02/06), Trial Chamber, 8 July 2019

Extraordinary African Chambers in the Courts of Senegal (EAC).

Ministère Public v. Hissein Habré, Extraordinary African Trial Chamber, 30 May 2016 International Crimes Division of the High Court of Uganda.

Prosecutor v. Kwoyelo Thomas alias Latoni (Case No. 02 of 2010), International Crimes Division of the High Court of Uganda at Kampala, 2017. 